\title{
Height and Self-Esteem as the Determinants of Psychological Adjustment in Students in Punjab, Pakistan
}

\author{
Muhammad Rizwan ${ }^{1 *} \quad$ Xuehong Qi ${ }^{1} \quad$ Dr. Iram Naz ${ }^{2} \quad$ Dr. Zaqia Bano ${ }^{2}$ \\ 1. School of Education Science, Nanjing Normal University, Nanjing, China \\ 2. Department of Psychology, University of Gujrat, Pakistan
}

\begin{abstract}
The purpose of the present research was to investigate height and self-esteem as the determinants of psychological adjustment in students. A sample of 300 students was recruited from University of Gujrat, Pakistan by using convenient sampling technique. The construct of self-esteem was measured using Rosenberg Self-esteem Scale whereas psychological adjustment was measured by using and Scale of Adjustment . The data was analyzed using neural network analysis. Among the 300 students, the results revealed that height and selfesteem predicted psychological adjustment. Further, the importance of each variable was also explored through the analysis. It indicated that the height of the students (.562 with $100 \%$ normalized importance) was more important in predicting the psychological adjustment as compare to self-esteem (.438 with $77.9 \%$ normalized importance). It was concluded that height and self-esteem was the determinant of psychological adjustment in students. Further, height plays a more vital role in hindering the psychological adjustment as compare to selfesteem.
\end{abstract}

Keywords: Height, Self-esteem, Psychological Adjustment, Neural Network Analysis, Students

DOI: $10.7176 / \mathrm{JEP} / 10-36-10$

Publication date: December $31^{\text {st }} 2019$

摘要

本研究旨在探讨身高与自尊对学生心理适应的影响。采用方便抽样技术，从巴基斯坦古吉拉特大学招收 了 300 名学生。自尊结构采用 Rosenberg 自尊量表进行测量, 心理适应采用和量表进行测量。数据采用 神经网络分析法进行分析。结果显示, 在 300 名学生中, 身高和自尊对心理适应有预测作用。此外, 还 通过分析探讨了各变量的重要性。结果表明, 与自尊 (438 人, $77.9 \%)$ 相比, 身高 (562人, 标准化重 要度为 $100 \%$ ）对心理适应的预测更为重要。结果表明, 身高和自尊是学生心理适应的决定因素。此 外, 与自尊相比，身高在阻碍心理适应方面起着更为重要的作用。

关键词：身高、自尊、心理调节、神经网络分析、学生

\section{INTRODUCTION}

Adjustment problems can be defined as the failure to give reaction effectively and sufficiently to the needs of one's environment (Srivastava \& Singha, 2017). Whereas maladjustment takes place when the relationship between an individual and his environment is not in accordance with the established standards or norms (Jose, 2010). The literature identified various reasons that can enhance maladjustment in persons like an introvert, neurotic or psychotics dispositions, authoritative parent, less understanding, attention, and care (Lee, \& Shu, 2016). The Diagnostic and Statistical Manual of Mental Disorders characterizes adjustment disorder with the characteristics of emotional and behavioral symptoms that were shown within the 3 months after encountering a stressor. It also gave specifiers of adjustment in terms of depression, anxious feelings, mixed depression and anxiety, conduct issues and mixed emotional and conduct disturbance (American Psychiatric Association, 2013). There are various variables associated with the adjustment level of university students as for example demographics information, locus of control, self-esteem, stress, personality and coping style (Dyson, \& Renk, 2006). Yaseen (2017) conducted a study in Pakistan to evaluate the prevalence of adjustment disorder and showed that the rate was $11.5 \%$ while the common stressors were illness and love affairs. The prevalence of adjustment was high with mixed anxiety and depressed mood. The psychological adjustment of the students may be limited due to many factors.

Among other factors affecting the psychological adjustment, the height of a person could be one of them. Height is defined as the depth of an individual from his or her head to foot. Further, it is can be the vertical length of an individual (Oxford dictionary, 2019). Height is also used to measure the growth of adolescents (Pawar \& Dadhich, 2012). Here, in this study psychological adjustment was specified on the indicators of depression, anxiety and conduct. Researches has established the fact that short height may trigger depression, anxiety and conduct problems in the person. It was witnessed that short heighted individuals may accompany depressive symptoms while dealing with the problem (Caffier, 2015). Further, another study on army personnel showed that persons with height problems were exposed to the symptoms of depression while ignoring the anxiety disorders (Krupnik, \& Cherkasova, 2014). 
Furthermore, self-esteem may also hinder the psychological adjustment of the students. Self-esteem is one of the most widely known constructs in psychology. This term has been described in innumerable ways. One of the most outstanding researchers in this area was done by Rosenberg who defined self-esteem as a positive or negative attitude towards oneself (Rosenberg, 1965). The investigation of self, emerged in psychology in the late nineteenth century. This typology of self is perceived as individuals' emotions about themselves from the connection with others. It explains that people have the ability to see themselves and hence have self-sentiments and dispositions toward themselves (Turner, 1998). The self-esteem can be improved by focusing on the traits and qualities and by avoiding superficial personality living around the low self-esteem individuals (Woolfe, 2019). Researches have strongly established the role of self-esteem in manipulating the adjustment of a person. A study has established the relation between self-esteem and adjustment of university students (Pasha \& Munaf, 2013). Further, a research project comprised of three studies identifying the role of self-esteem and adjustment. It was concluded that problematic self-esteem leads to adjustment problems. A person with inferior self-esteem shows feelings of sadness and depression whereas superior self-esteem linked with nervousness. These may resultant in lowering the adjustment level (Zeigler-Hill \& Wallace, 2012). Another study established the fact that social adjustment can be directly affected by the self-esteem in adolescents (Gao et al., 2019).

The current study was conducted to foresee height and self-esteem as the determinants of psychological adjustment in students. It is of great importance to identify the problems pertaining to psychological adjustment of students in Pakistan. The findings of the research confirmed the existing literature related to study variables in Pakistan. Besides, the factor of height with special reference to psychological adjustment in Pakistan was not studied comprehensively.

\section{METHOD}

\section{Participants}

The sample of 300 students was employed (144 Girls \& 156 Boys) in the research with mean age of 24.50 years $( \pm \mathrm{SD}=3.75)$, from University of Gujrat,Punjab, Pakistan. The sample selected using convenient sampling technique.

Measures

The data was collected using a scale battery comprised of demographic form, Rosenberg Self-esteem Scale (Rosenberg, 1989) and Scale of Adjustment English version (Naz \& Sehrish, 2018) to measures the psychological adjustment of students.

The demographic form includes the variable of age, gender, heights and area of living (rural or urban). The self-esteem scale was based on 10 statements that measure a person's self-worth. It includes the negative and positive feelings of a person about him or herself. It is doesn't include any subscale. The items are rated on 4point Likert from strongly agree to strongly disagree (Rosenberg, 1989). The adjustment scale was developed on the adjustment disorder criteria (American Psychiatric Association, 2013) and Beck Model (Beck, 1964). The scale comprised of 48 items with 8 sub-scales related to depression, anxiety, and conduct. The reliability was between .711 to .938 with established validity of the scale.

Procedure

The participates were recruited on volunteer and unidentified bases. The sample of the study was selected using a non-probability convenient sampling technique. The sample was comprised of students. The objectives of the research, its material, and procedures were studied and discussed with psychologists at University of Gujrat, Pakistan. The procedure of the study incorporated all the suggestions. The important ethical considerations were followed in the study (Lindsay, 2000). The sample was gathered from University of Gujrat. The detail description of the research was given to the students. Further, they were provided with detailed instructions and explained about the study and its revealing benefits. The respondents were also warranted about secrecy and confidentiality of their identity. Both oral and written consent from the respondents were taken. Before administrating the scales, rapport was built with the students. After that, the demographic form, scale of adjustment and self-esteem was filled out by the respondents. The students were asked to read the items carefully and give a response that matches their state of mind. The permission for use of all the scales in the present research was obtained from the authors through email. At the end of data collection, the researcher uttered gratitude to the students in completing the research.

Statistical Analysis

The data of the study were analyzed by using neural network analysis. Neural network analysis was used to foresee the role of height and self-esteem as the determinant of psychological adjustment in students. Hence, height and self-esteem play a role in regulating the psychological adjustment that will be explored in this analysis.

\section{RESULTS}

The neural network analysis was used to explore the height and self-esteem as the determinants of psychological 
adjustment in students.

Table 1

Predictor Association among Variables based on Training and Testing Relative Error $(N=300)$

\begin{tabular}{cc}
\hline & Relative Error \\
\hline Training & Testing \\
\hline .906 & .957 \\
\hline
\end{tabular}

The neural network presents a relative error for training and testing as shown in Table 1 . It has been appraised that the less the difference in the training and testing relative errors, the established the predictive association among the independent and dependent variables. The current study witnessed a very minor difference. It was confirmed that height and self-esteem was the determinants of psychological adjustment in students.

Table 2

Predictive Importance of Height and Self-esteem in predicting the Self-esteem of Students

\begin{tabular}{lllc}
\hline Sr\# & Variables & Importance & Normalized Importance \\
\hline $\mathbf{1}$ & Self-esteem & .438 & $77.9 \%$ \\
$\mathbf{2}$ & Height & .562 & $100.0 \%$ \\
\hline
\end{tabular}

The model of neural network analysis presents the importance of each independent variable on the dependent variable. The predictive importance of height and self-esteem on the psychological adjustment of students was inspected. The result showed that the most important predictor of psychological adjustment of students was the height .562 with $100 \%$ normalized importance. On the other side self-esteem of students also predict the psychological adjustment .438 with $77.9 \%$ normalized importance. Among the two the height contributed more to the adjustment of a student as compared to self-esteem but both the variables predict the psychological adjustment. The importance can be seen in Figure 1.

\section{Normalized Importance}

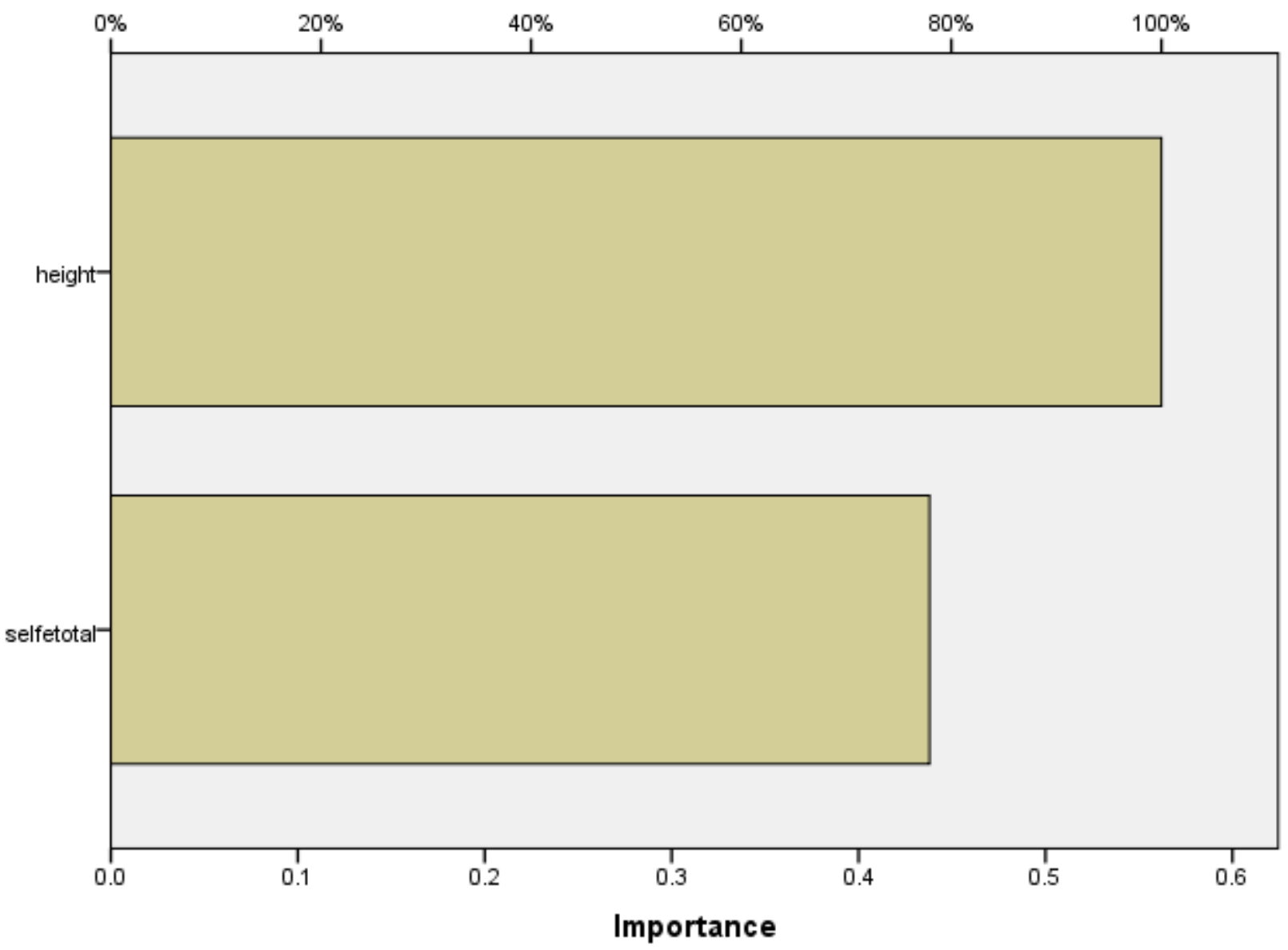

Figure 1 Importance of Prediction of Height and Self-esteem for Psychological Adjustment of Students

\section{DISCUSSION}

The current study's aim was to investigate height and self-esteem as the determinants of psychological adjustment in students. 
The findings of neural network analysis established the predictive relationship among variables with a very minor difference in training and testing relative error (.051). This less difference indicated that the model is not overtrained. The effect of height and self-esteem on the psychological adjustment of students was proven with the importance ratio of $.562(100 \%$ normalized importance) and .438 ( $77.9 \%$ normalized importance) respectively.

Casey and Bailey (2011) foresee adjustment in various clinical settings and concluded that adjustment problem was about 3 times more common as the depression and the most common mental disorder was adjustment disorder. Another study assesses the prevalence of anxiety and reported that it was $8.2 \%$ (Maideen, Sidik, Rampal \& Mukhtar, 2015) Whereas the conduct issues may be related to one's job, relationships and illegal problematic behaviors (Dresden, 2017).

The previous researches also established the linked between height and self-esteem as the determinant of psychological adjustment. The adjustment was measured on depression, anxiety and conduct issues (American Psychiatric Association, 2013) in the current study. However, there was very little research available that recognized the role of height in affecting the psychological adjustment of students. The factor of depression was seen in persons with height related issues (Caffier, 2015 \& Krupnik, \& Cherkasova, 2014) whereas the role height in triggering anxiety was subject to rejection (Krupnik, \& Cherkasova, 2014). It was viewed that betterheighted persons were more likely to go on with their higher studies. Further, it was reported that after controlling the role of cognitions there were unconscious biases existed in the educationists related to boosting the taller students (Freeman \& Freeman, 2014).

In case of self-esteem triggering the psychological adjustment, its importance cannot be denied after study the literature. There was strong literature confirmation available that established the relationship among the variables. In university students, there was a link foreseen in the self-esteem and adjustment (Pasha \& Munaf, 2013). Further, Zeigler-Hill \& Wallace, (2012) also proven linked between self-esteem and adjustment problems. Social adjustment may also hinder the self-esteem in adolescents (Gao et al., 2019).

\section{Conclusion}

It was concluded that height and self-esteem was the determinant of psychological adjustment in students. Further, height plays a more important role in affecting psychological adjustment as compare to self-esteem.

This study surely helps to create management plans for students. This research also provides a new horizon and information for new researches. Findings of the study are also helpful for academicians and policy maker to overcome these problems in students. There must be new awareness programs which can enhance the adjustment. In future researchers must studied other problems and determinants. A qualitative in-depth study may also be done.

\section{REFERENCES}

American Psychiatric Association. (2013). Diagnostic and statistical manual of mental disorders (5 $5^{\text {th }}$ ed.). Washington, D.C: American Psychiatric Association.

Beck, A.T. (1964). Thinking and Depression II. Theory and Therapy. Archives of General Psychiatry, 10(6), $561-571$.

Booth, N.D. (1990). The Relationship between Height and Self-Esteem and the Mediating Effect of SelfConsciousness. The Journal of Social Psychology, 130(5), 609-617. DOI: 10.1080/00224545.1990.9922952

Caffier, J. (2015). Science Says Being Short Makes You Depressed. Retrieved from https://www.vice.com/en_us/article/7bd7jb/it-sucks-to-be-a-short-guy-511

Casey, P., \& Bailey, S. (2011). Adjustment disorders: The state of the art. World Psychiatry, 2(1), 10-18. https://doi.org/10.1002/j.2051-5545.2011.tb00003.x

Dresden, D. (2017). Conduct disorder: What you need to know. Retrieved from https://www.medicalnewstoday.com/articles/320386.php

Dyson, R., \& Renk, K. (2006). Freshmen adaptation to university life: Depressive symptoms, stress, and coping. Journal of Clinical Psychology, 62(10), 1231-1244

Freeman, D., \& Freeman, J. (2014). Does Our Height Influence Our Mental Health? Retrieved from https:/www.psychologytoday.com/us/blog/know-your-mind/201401/does-our-height-influence-our-mentalhealth

Gao, F., Yao, Y., Yao, C., Xiong, Y., Ma, H \& Liu, H. (2019). The mediating role of resilience and self-esteem between negative life events and positive social adjustment among left-behind adolescents in China: a cross-sectional study. BMC Psychiatry, 19, doi:10.1186/s12888-019-2219-z

Jose, J. (2010). Types of adjustment in psychology. Retrieved from https://www.indiastudychannel.com/resources/131499-Types-of-adjustment

Krupnik, V., \& Cherkasova, M. V. (2014). Size Matters Stature Is Related to Diagnoses of Depression in Young Military Men. SAGE Open. https://doi.org/10.1177/2158244014542783 
Lee, F.Y., \& Shu, B.C. (2016). The premorbid personality in military students with adjustment disorder. Military Psychology, 18(1), 77-88.

Lindsay, G. (2000). Researching children's perspectives: ethical issues. In A. Lewis \& G. Lindsay (Eds.), Researching Children's Perspectives (pp. 3-20). Buckingham: Milton Keynes.

Maideen, S.F.K., Sidik. S.M., Rampal. L., \& Mukhtar, F. (2015). Prevalence, associated factors and predictors of anxiety: a community survey in Selangor, Malaysia. BMC Psychiatry, 15, DOI 10.1186/s12888-015-0648-x

Naz, I., \& Sehrish. (2018). Translation, Adaptation and Validation of Scale of Adjustment for Adults. Unpublished Masters dissertation, Faculty of Social Sciences, University of Gujrat, Gujrat-Pakistan.

Oxford dictionary (2019). Definition of height in English. Retrieved from https://en.oxforddictionaries.com/definition/height

Pawar, P.K., \& Dadhich, A. (2012). Study of correlation between Human height and hand length in residents of Mumbai. International Journal of Biological and Medical Research, 3, 2072-2075.

Rosenberg, M. (1965). Society and the adolescent self-image. Princeton, NJ: Princeton University Press.

Rosenberg, M. (1989). Society and the Adolescent Self-Image. Revised edition. Middletown, CT: Wesleyan University Press.

Srivastava, P.S., \& Singha, P. (2017). Adjustment problems of high and low academic achievers. Inter Journal of Advance Educational Research, 2 (4), 175-18.

Turner, J. H. (1998). The Structure of Sociological Theory. 6th ed. Belmont, CA: Wadsworth Publishing Company.

Woolfe, S. (2019). How Being Short as a Man Can Affect Your Self-Esteem - and What You Can Do About It. Retrieved from https://www.blakewrites.com/articles/how-being-short-as-a-man-can-affect-your-selfesteem-and-what-you-can-do-about-it

Yasmeen, Y.A. (2017). Adjustment disorder: Prevalence, sociodemographic risk factors, and its subtypes in outpatient psychiatric clinic. Asian Journal of Psychiatry, 28, 82-85.

Zeigler-Hill, V., \& Wallace, M. T. (2012). Self-esteem instability and psychological adjustment. Self and Identity, 11, 317-342. 